\title{
Hubungan Indeks Massa Tubuh dengan Cedera Ligamen Krusiat Anterior pada Atlet Cabang Olahraga Kontak
}

\author{
Rurin Ardiyanti ${ }^{1}$, Afriwardi ${ }^{2}$, Nur Afrainin Syah ${ }^{3}$
}

\begin{abstract}
Abstrak
Cedera Ligamen Krusiat Anterior (LKA) adalah trauma pada atlet yang memerlukan tindakan bedah dan berrisiko menjadi osteoartritis. Berbagai macam faktor dapat menyebabkan cedera LKA, seperti Indeks Massa Tubuh (IMT) yang merupakan salah satu faktor risiko cedera LKA. Tujuan penelitian ini adalah menentukan hubungan IMT dengan cedera LKA. Penelitian ini menggunakan metode analitik observasional. Sampel adalah 271 atlet diambil dari seluruh cabang olahraga kontak di KONI (Komite Olahraga Nasional Indonesia) Jawa Timur. Data yang diperoleh berupa IMT dan kejadian cedera LKA pada atlet dalam 1 tahun, kemudian dianalisis dengan uji kemaknaan Fisher. Peneliti menemukan 7\% (19 orang) mengalami cedera LKA. Penelitian ini menemukan bahwa presentase cedera LKA pada IMT tinggi $\left(>24,9 \mathrm{~kg} / \mathrm{m}^{2}\right)$ dua kali lebih banyak dibanding pada IMT tidak tinggi $\left(\leq 24,9 \mathrm{~kg} / \mathrm{m}^{2}\right)$, yaitu $12,5 \%$ dan $6,5 \%$. Pada uji Fisher tidak ditemukan hubungan antara IMT dan cedera LKA $(p>0,05)$. Penelitian ini menunjukkan bahwa terdapat risiko cedera LKA pada atlet dengan IMT tinggi, namun tidak signifikan secara statistik. Banyak faktor risiko cedera LKA lainnya yang tidak dapat dikontrol melalui metodologi penelitian ini.
\end{abstract}

Kata kunci: indeks massa tubuh, cedera ligamen krusiat anterior, atlet

\begin{abstract}
Anterior Cruciate Ligament (ACL) injuries are common on athletes that need surgical treatment and a risk to become osteoarthritis. There are many factors contributed to ACL injury. Body Mass Index (BMI) is one of ACL injury risk factor. The objective of this study was to determine the relationship between BMI and ACL injury. This was an observasional analitic study. The sample was 271 contact sport athletes at KONI East Java. Data about BMI and ACL injury on the athlete for 1 year was collected. The data then was analysed by Fisher test. There were 7\% (19 persons) of athletes suffers from ACL injury. This study found that the proportion of ACL injury on athlete with high BMI (>24,9 $\left.\mathrm{kg} / \mathrm{m}^{2}\right)$ was twice compared to athlete without high $B M I\left(\leq 24,9 \mathrm{~kg} / \mathrm{m}^{2}\right), 12,5 \%$ and $6,3 \%$ respectively. The conclusion is the different is not significant statitically. This study showed that high BMI on athletes was a risk factor for ACL injury but not significant statistically.
\end{abstract}

Keywords: body mass index, anterior cruciate ligament, athlete

Affiliasi penulis: 1. Prodi Profesi Dokter FK UNAND (Fakultas Kedokteran Universitas Andalas Padang), 2. Bagian Fisiologi FK UNAND, 3. Bagian Anatomi FK UNAND

Korespondensi: Rurin Ardiyanti, Email: rurinardiyanti@ymail.com, Telp: 085733033966

\section{PENDAHULUAN}

Ligamen Krusiat Anterior (LKA) adalah salah satu ligamen yang bersilangan pada lutut dan berfungsi sebagai pengikat utama antara femur dan tibia. ${ }^{1}$ Cedera LKA merupakan cedera yang sering terjadi pada atlet, memerlukan tindakan bedah dan memiliki gejala sisa yang serius. ${ }^{2}$ National Center for Chronic Disease Preventive \& Health Promotion (NCCDPHP) Amerika Serikat tahun 2009, menyatakan terjadinya peningkatan prevalensi cedera LKA dalam dekade terakhir. Peningkatan ini dihubungkan dengan bertambahnya jumlah penduduk yang berpartisipasi dalam aktivitas fisik. ${ }^{3}$ Insiden pastinya belum diketahui, namun dilaporkan sekitar 200.000 kasus cedera LKA, dan 100.000 kasus rekonstruksi LKA setiap tahunnya 
di Amerika Serikat. ${ }^{4}$ Insiden tertinggi terjadi pada usia 15-25 tahun, yaitu pada atlet yang melakukan gerakan memutar sendi lutut seperti atlet sepak bola, basket, European handball dan bola voli. ${ }^{5}$

Penelitian di Norwegia, Denmark dan Swedia pada tahun 2004-2006 mendapatkan insiden cedera LKA tertinggi pada perempuan yang berusia 15-19 tahun. $^{6}$ Sebuah studi di West Point Inggris, melaporkan kejadian cedera LKA sebanyak 3,2\% pada laki-laki dan $3,5 \%$ pada perempuan selama periode 4 tahun. Penelitian lain menunjukkan tingkat cedera pada atlet perempuan berkisar dua sampai enam kali lipat dibandingkan dengan atlet laki-laki, tergantung pada olahraga yang diteliti. ${ }^{7}$ Thailand National Games pada tahun 2008, mengumpulkan insiden cedera olahraga berdasarkan cabang olahraga yang dipertandingkan. Penelitian epidemiologi ini melaporkan insiden cedera olahraga sebesar $8,1 \%$ untuk cabang olahraga kontak penuh, sebesar $8,3 \%$ untuk cabang olahraga kontak terbatas dan hanya $1,8 \%$ untuk cabang olahraga tanpa kontak. Penelitian ini menyimpulkan bahwa cabang olahraga kontak penuh dan kontak terbatas memiliki risiko potensial untuk terjadinya cedera saat kompetisi. ${ }^{8}$

Masalah cedera LKA sangat penting karena rusaknya LKA akan menyebabkan osteoarthritis prematur. Penelitian dengan membandingkan gambaran radiografi perempuan berusia 26-40 tahun, menunjukkan bahwa penderita cedera LKA di masa remaja, memiliki prevalensi osteoarthritis dan keterbatasan fungsional yang lebih tinggi. $^{9}$ Osteoarthritis diperkirakan terjadi pada $50 \%$ atlet cedera LKA, dalam rentang waktu 10 sampai 20 tahun setelah cedera. Hal ini berarti mereka menderita osteoartritis di usia yang masih muda. ${ }^{7}$ Meskipun telah dilakukan bedah rekonstruksi pada penderita cedera LKA, kejadian artritis degeneratif pasca trauma masih ditemukan. $^{10}$

Banyak hal yang dapat meningkatkan risiko cedera LKA, baik yang berasal dari luar (faktor ekstrinsik) maupun faktor dari atlet (faktor intrinsik). Faktor ekstrinsik yang mungkin mempengaruhi terjadinya cedera LKA adalah cabang olahraga, cuaca, dan kondisi tempat latihan, serta alas kaki yang digunakan. Faktor intrinsik yang mungkin akan mempengaruhi terjadinya cedera LKA adalah jenis kelamin, anatomi Indeks Massa Tubuh (IMT), faktor hormonal, riwayat keluarga cedera LKA, riwayat cedera sebelumnya, dan fungsi neurokognitif. Dari faktor risiko diatas, IMT merupakan faktor risiko yang dapat dimodifikasi. IMT yang lebih tinggi dari normal memiliki faktor risiko terjadinya cedera LKA. Penelitian yang dilakukan pada kadet (mahasiswa akademi militer) perempuan di Amerika Serikat menunjukan IMT yang lebih tinggi dari rata-rata merupakan faktor risiko cedera LKA. Penelitian ini belum pernah dilakukan pada laki-laki. ${ }^{11}$ Penelitian lain yang juga dilakukan di Amerika Serikat menyatakan bahwa pemeliharaan IMT dalam batas normal, berpotensi meningkatkan hasil rekontruksi LKA secara fungsional dalam jangka waktu panjang. ${ }^{12}$ Maka penting dilaksanakan penelitian untuk mengetahui hubungan antara IMT dengan cedera LKA, sehingga dapat dilakukan pencegahan terhadap cedera dengan memperbaiki angka IMT.

Berdasarkan latar belakang tersebut, perlu diteliti hubungan IMT dengan cedera LKA pada atlet cabang olahraga kontak di KONI Provinsi Jawa Timur.

\section{METODE}

Penelitian ini merupakan penelitian analitik observasional dengan desain cross sectional yang dilakukan di Komite Olahraga Nasional Indonesia (KONI) Jawa Timur di Surabaya. Penelitian dilaksanakandari Maret 2014-November 2014 di KONI Jawa Timur di Surabaya. Populasi penelitian adalah seluruh atlet cabang olahraga kontak di KONI Jawa Timur. Penelitian ini menggunakan metode total sampling. Seluruh atlet cabang olahraga kontak, dijadikan sampel selama mereka tidak termasuk dalam kriteria eksklusi, yang berjumlah 271 orang.

Variabel dependen pada penelitian ini adalah kejadian cedera LKA yang dinyatakan melalui hasil medical check up pada atlet cabang olahraga kontak . Hasil ukurnya yaitu cedera LKA dan tidak cedera LKA. Variabel independen (bebas) pada penelitian ini adalah IMT yang didapat dari hasil medical check up pada atlet cabang olahraga kontak. Hasil ukurnya yaitu IMT tinggi $\left(>24,9 \mathrm{~kg} / \mathrm{m}^{2}\right)$ dan IMT tidak tinggi $\left(\leq 24,9 \mathrm{~kg} / \mathrm{m}^{2}\right)$. Variabel perancu pada penelitian ini 
adalah hormonal, riwayat keluarga cedera LKA, kontrol neuromuscular rendah, fungsi kognitif rendah, riwayat cedera sebelumnya dan cabang olahraga. Pengaruh variabel perancu diminimalisir semaksimal mungkin melalui penetapan kriteria eksklusi.

Data penelitian diperoleh dari medical check up atlet cabang olahraga kontak di KONI Jawa Timur. Analisis data terdiri dari analisis univariat dan bivariat. Analisis bivariat dilakukan dengan uji chi square untuk mengetahui hubungan antara variabel dependen dan variabel independen dengan derajat kemaknaan 0,05. Jika jumlah subyek total $\mathrm{n}<20$ atau jumlah subyek antara 20-40 dengan nilai expected ada yang $<5$, maka dipakai uji mutlak Fisher. Bila nilai $p<\alpha(0,05)$ maka hasil perhitungan statistik bermakna (signifikan).

\section{HASIL}

\section{Analisis Univariat}

Tabel 1. Gambaran cedera LKA pada atlet cabang olahraga kontak di KONI Jawa Timur

\begin{tabular}{lcc}
\hline \multicolumn{1}{c}{ Cedera LKA } & F & $\%$ \\
\hline Cedera LKA & 19 & 7.0 \\
Tidak cedera LKA & 252 & 93.0 \\
\hline Jumlah & 271 & 100 \\
\hline
\end{tabular}

Kejadian cedera LKA pada atlet cabang olahraga kontak cukup kecil yaitu 19 responden (7\%). Cabang olahraga wushu memiliki kejadian cedera LKA terbanyak, yaitu empat atlet.

Tabel 2. Gambaran IMT pada atlet cabang olahraga kontak di KONI Jawa Timur

\begin{tabular}{ccc}
\hline IMT & f & $\%$ \\
\hline$>24.9 \mathrm{~kg} / \mathrm{m}^{2}$ (IMT tinggi) & 32 & 11.8 \\
$\leq 24.9 \mathrm{~kg} / \mathrm{m}^{2}$ (IMT tidak tinggi) & 239 & 88.2 \\
\hline Jumlah & 270 & 100 \\
\hline
\end{tabular}

Sebagian besar atlet cabang olahraga kontak di KONI Jawa Timur memiliki IMT tidak tinggi ( $\leq 24.9$ $\mathrm{kg} / \mathrm{m}^{2}$ ) yaitu sebesar $88,2 \%$.

\section{Analisis Bivariat}

Presentase kejadian cedera LKA pada kelompok IMT tinggi lebih banyak dari presentase kejadian cedera LKA pada kelompok IMT tidak tinggi (12,5\% berbanding 6,3\%). Uji Fisher yang dilakukan untuk menilai hubungan antara 2 variabel tersebut menunjukkan bahwa tidak terdapat hubungan yang bermakna antara IMT dengan kejadian cedera LKA pada atlet cabang olahraga kontak di KONI Jawa Timur $(p>0,05)$.

Tabel 3. Kejadian cedera LKA pada atlet cabang olahraga kontak di KONI Jawa Timur berdasarkan kelompok IMT

\begin{tabular}{|c|c|c|c|c|c|c|}
\hline \multirow[t]{2}{*}{ IMT } & \multicolumn{2}{|c|}{ Cedera LKA } & \multicolumn{2}{|c|}{$\begin{array}{c}\text { Tidak cedera } \\
\text { LKA }\end{array}$} & \multirow[t]{2}{*}{ Jumlah } & \multirow[t]{2}{*}{$p$} \\
\hline & $F$ & $\%$ & $F$ & $\%$ & & \\
\hline $\begin{array}{l}\text { IMT } \\
\text { tinggi }\end{array}$ & 4 & 12.5 & 28 & 87.5 & 32 & \\
\hline $\begin{array}{c}\text { IMT } \\
\text { tidak } \\
\text { tinggi }\end{array}$ & 15 & 6.3 & 224 & 93.7 & 239 & 0.257 \\
\hline Jumlah & 19 & 7.0 & 252 & 93.0 & 271 & \\
\hline
\end{tabular}

\section{PEMBAHASAN}

\section{Frekuensi Cedera LKA pada atlet}

Cedera LKA merupakan cedera ligamen lutut yang serius, yang dapat menyebabkan hambatan dalam ketangkasan, dan merupakan cedera yang relatif sering pada individu yang aktif berolahraga diseluruh dunia. ${ }^{13}$ Penelitian yang dilakukan di Australia pada pertandingan musiman Australian Football League menemukan bahwa angka kejadian cedera LKA mencapai 0,9\% setiap musim dari 2672 atlet. ${ }^{14}$ Penelitian lain di Amerika Serikat meliputi 9 juta atlet menyatakan bahwa $6,5 \%$ atlet mengalami cedera LKA baik saat pertandingan maupun saat latihan. ${ }^{15}$ Hasil penelitian di Amerika tersebut tidak jauh berbeda dengan hasil penelitian saya di KONI Jawa Timur pada atlet cabang olahraga kontak, yaitu 7\%.

Atlet memiliki risiko yang tinggi untuk mengalami cedera LKA karena melakukan gerakan seperti mendarat dari melompat, berputar dan mengganti arah. Gerakan-gerakan tersebut berperan penting dalam mekanisme cedera LKA. ${ }^{13}$

\section{Gambaran IMT pada atlet}

Penelitian ini mendapatkan bahwa pada atlet cabang olahraga kontak 88,2\% mempunyai IMT tidak 
tinggi $\left(24,9 \mathrm{~kg} / \mathrm{m}^{2}\right)$ dan $11,8 \%$ memiliki IMT tinggi $\left(>24,9 \mathrm{~kg} / \mathrm{m}^{2}\right)$. Hasil yang didapat dari penelitian di KONI Jawa Timur ini hampir sama dengan hasil penelitian pada sekolah di Amerika Serikat. Penelitian yang dilakukan pada atlet laki-laki di Fairfax County Public School Distric di Amerika Serikat menemukan sebanyak $85,6 \%$ atletnya memiliki IMT tidak tinggi dan $14,4 \%$ memiliki IMT tinggi. ${ }^{16}$ Penelitian lain yang dilakukan pada atlet perempuan di Amerika Serikat yang meliputi 11 sekolah menemukan bahwa 95,9\% atlet memiliki IMT tidak tinggi dan 4,1\% atlet memiliki IMT tinggi. ${ }^{17}$

Sebagian besar atlet tidak memiliki IMT tinggi karena atlet membutuhkan banyak zat gizi untuk membentuk energi selama otot berkontraksi. Sebagian besar energi diperoleh dari karbohidrat selama beberapa detik atau menit pertama olahraga. Olahraga pada menit berikutnya, sebanyak 60-85\% energi didapatkan dari lemak. Sejumlah besar lemak yang digunakan sebagai energi, biasanya diperoleh dalam bentuk asam lemak dan asam asetoasetat pada cadangan lemak tubuh. ${ }^{18}$

\section{Hubungan Indeks Massa Tubuh dengan Cedera LKA}

Hasil penelitian ini menemukan kejadian cedera LKA sebesar $7 \%$ dari seluruh atlet. Atlet dengan IMT tidak tinggi $\left(\leq 24,9 \mathrm{~kg} / \mathrm{m}^{2}\right)$ kejadian cedera LKA adalah sebesar 6,3\%, sedangkan atlet dengan IMT tinggi $\left(>24,9 \mathrm{~kg} / \mathrm{m}^{2}\right)$ kejadian cedera LKA adalah sebesar $12,5 \%$. Berdasarkan hasil uji Fisher menggunakan didapatkan $\mathrm{p}>0,05$, berarti tidak terdapat hubungan yang bermakna antara IMT dengan cedera LKA pada atlet cabang olahraga kontak di KONI Jawa Timur. Hasil penelitian ini menunjukkan bahwa terdapat risiko cedera LKA pada atlet IMT yang tinggi $\left(>24,9 \mathrm{~kg} / \mathrm{m}^{2}\right)$, tetapi tidak signifikan secara statistik.

Penelitian sebelumnya yang dilakukan pada kadet (mahasiswa akademi militer) perempuan di Amerika Serikat menunjukan IMT yang lebih tinggi dari rata-rata merupakan faktor risiko cedera LKA. Penelitian ini menjelaskan bahwa faktor risiko IMT pada cedera LKA hanya signifikan pada kadet perempuan. Faktor risiko yang signifikan pada kadet laki-laki adalah lebar insisura interkondilar dan kelemahan sendi yang general. Penelitian di KONI Jawa timur in tidak hanya menggunakan atlet perempuan sebagai subjek, melainkan juga menggunakan atlet laki-laki untuk menguji faktor risiko IMT pada kejadian cedera LKA. Faktor risiko cedera LKA yang signifikan pada laki-laki seperti lebar insisura interkondilar dan kelemahan sendi yang general tidak dipertimbangkan. Hal ini mungkin menyebabkan perbedaan hasil penelitian saya dengan penelitian Uhorchak et al (2003). ${ }^{11}$

\section{KESIMPULAN}

Tidak terdapat hubungan IMT dengan cedera LKA pada atlet cabang olahraga kontak di KONI Jawa Timur.

\section{DAFTAR PUSTAKA}

1. Snell R. Anatomi klinik untuk mahasiswa kedokteran (terjemaahan). Edisi ke-6. Jakarta: EGC; 2006.

2. Smith $H$, Vecek $P$, Johnson $R$, et al. Risk factor for anterior cruciate ligament injury: a review of the literature. Sports Health. 2012;4(2):155-61.

3. Nation Center Of Chronic Disease Prevention \& Health Promotion. Behavioral risk factor surveillance system. 2009. (diunduh 28 Maret 2014). Tersedia dari: URL: HYPERLINK http://apps.nccd.cdc.gov/BRFSS/display.asp?state $=$ US\&cat=PA\&yr=0\&qkey=4418\&grp=0\&SUBMIT4 $\equiv$ Go.

4. Campbell W. Operative orthopaedics. Edisi ke-11. Philadelphia: Elsevier; 2008.

5. Griffin L, Agel J, Albohm M, et al. Noncontact anterior cruciate ligament injury: risk factors and prevention strategies. The journal of the American Academy of Orthopaedic Surgeon. 2000;8(3):14150.

6. Renstrom $P$, Ljungqvist $A$, Arendt $E$, et al. Noncontact ACL injury in female athlete: an international olympic committee current concepts statement. British Journal Sports Medicine. 2008;42:394-412.

7. Splinder K, Rick W. ACL tears. The New England Journal of Medicine. 2008;359(20):2135-42. 
8. Laoruengthana $\mathrm{A}$, Poosamsai $\mathrm{P}$, Fangsanau $\mathrm{T}$, et al. The epidemiology of sports injury during the 37th Thailand national games 2008 in Phitsanulok. J Med Assoc Thai. 2009;92(6):204-10.

9. Lohmander L, Ostenberg A, Englund M, et al. High prevalence of knee osteoarthritis, pain, and fuctional limitations in female soccer players twelve years after ligament krusiat anterior injury. Arthritis and Rheumatism. 2004;50(10):3145-52.

10. Daniel D, Stone D, Dobson B, et al. Fate of the ACL-injured patient: a retrospective outcame study. The American Journal of Sports Medicine. 1994;22(5):632-44.

11. Uhorchak J, Scoville C, Williams G, et al. Risk factors associated with noncontact injury of the anterior cruciate ligament: a prospective four years evaluation of 859 West Point cadets. American Journal of Sports Medicine. 2003;31:831-42.

12. Bowers A, Spindler K, McCarty E, et al. Height, weight and $\mathrm{BMI}$ predict intra-articular injury observed during $A C L$ recontruction: evaluation of 456 case from a prospective ACL database. Clin J Sports Med. 2005;15(1):9-13.
13. Serpell B, Scarvell J, Ball N, et al. Mechanism and risk factors for noncontact $A C L$ injury in age mature athlete who engange in field or court sports : A summary literature since 1980 . Journal os Strength \& Editoring Research. 2012;26(11):3160-76.

14. Orchad J, Seward H. Epidemiology of injuries in the australian footbal league season 1997-2000. British Journal Sports Medicine. 2002;36 :39-45.

15. Joseph A, Collins C, Henke N, et al. A multisport epidemiologic comparison of anterior cruciate ligament in high school atletics. Journal of Atletics Training. 2013;48(6):810-7.

16. Choate N, Foster C, Almquist J, et al. The Prevalence of overweight in participants in high school extramural sports. Journal of Adolesent Health. 2006;4:283-5.

17. Johnson C, Powers P, Dick R. Athletes and eating disorders: the national collegiate athletic association study. International Journal Eat Disorder. 1999;26:179-88.

18. Guyton A, Hall J. Buku ajar fisiologi kedokteran (terjemahan). Jakarta: EGC; 2007. 